\title{
Bacille Calmette-Guérin vaccination of healthcare personnel: changing epidemiology calls for new recommendations in Norway
}

\author{
Trude M. Arnesen ${ }^{1}$, Arne B. Brantsæter ${ }^{2}$ and Hanne Nøkleby ${ }^{1}$ \\ Affiliations: ${ }^{1}$ Norwegian Institute of Public Health, Oslo, Norway. ${ }^{2}$ Oslo University Hospital, Oslo, Norway. \\ Correspondence: Trude M. Arnesen, Norwegian Institute of Public Health, SMSB, PB 222 - Skøyen, 0213 Oslo, \\ Norway. E-mail: trude.arnesendfhi.no
}

@ERSpublications

Low risk of tuberculosis in Norway prompts abandoning a policy of universal BCG vaccination of all health students and personnel http://ow.ly/2lYW30mIVRN

Cite this article as: Arnesen TM, Brantsæter AB, Nøkleby H. Bacille Calmette-Guérin vaccination of healthcare personnel: changing epidemiology calls for new recommendations in Norway. Eur Respir J 2019; 53: 1801123 [https://doi.org/10.1183/13993003.01123-2018].

Until 2018, bacille Calmette-Guérin (BCG) vaccination was strongly recommended for all unvaccinated personnel and students in the healthcare sector in Norway. From June 2018, only a select group of students and healthcare personnel have been targeted for BCG vaccination, i.e. previously unvaccinated healthcare workers and students under 35 years of age who are caring for adult patients with pulmonary tuberculosis (TB) in hospitals or involved with mycobacterial culture in laboratories. What was the rationale behind this policy change?

\section{A short history of BCG in Norway}

In 2009, Norway was one of the last Western European nations to abandon universal BCG vaccination [1]. Until then, all tuberculin-negative schoolchildren were vaccinated at the age of 12-14 years. In addition, both before and after 2009, vaccination was recommended for newborns with parents from high-incidence countries, for all students and employees $<35$ years of age in the healthcare sector, and for individuals $<35$ years of age planning a long-term stay in a country with high incidence of TB (table 1) [2].

Norway's extensive BCG vaccination policies may have been influenced by pioneer studies in the 1920s and 1930s conducted by the physicians Johannes Heimbeck and Olaf Scheel at Ullevål Hospital in Oslo [3]. At a time when Norway had very high TB prevalence, they found that one-half of nursing school students were tuberculin-negative when they started their studies, and all were positive after 3 years, indicating high rates of new infection [4]. Out of 284 tuberculin-negative students who were not vaccinated, 97 fell ill with TB during their studies and 10 died [3]. By administering BCG to volunteer tuberculin-negative nursing and medical students, Heimbeck and Scheel observed a protective effect against TB of 80\% [2].

\section{Need to revaluate BCG vaccination recommendations for healthcare personnel}

In 2014, 5 years after routine adolescent BCG vaccination was discontinued, the first cohort of unvaccinated individuals started healthcare studies. Practical difficulties related to BCG vaccination of healthcare employees and students had been anticipated, and indeed soon appeared. A main obstacle was 
TABLE 1 Bacille Calmette-Guérin strategies in Norway from 1948 to today

Until 2009

Obligatory 1948-1994
Voluntary 1995-2009
Recommended (since 1970s)
Required by most employers
Recommended

2009-2018

Not recommended Not recommended

Recommended

Recommended

Recommended
Recommended

Select groups only"

Recommended

\#: in the early period of obligatory vaccination, all unvaccinated tuberculin-negative persons up to 40-50 years, including health personnel, were also targeted. " : previously unvaccinated healthcare personnel and students $<35$ years of age with work involving care for adult patients with pulmonary tuberculosis in hospitals or culture of mycobacteria in laboratories.

that the healthcare institutions offering practice placements for students are legally responsible for vaccination, even though the students' educational institutions are better suited to organise this. Furthermore, BCG recommendations had been changed in neighbouring countries since 2009. This prompted the Norwegian Institute of Public Health to re-examine the rationale for maintaining BCG vaccination among employees and students in the healthcare sector. A preliminary report was prepared, addressing national TB epidemiology, studies on BCG vaccine protective effect in adults, cost of vaccination and recommendations for BCG vaccination in other countries.

\section{TB epidemiology}

TB incidence in Norway is among the lowest in the world. In 2017, the total number of TB cases notified to the Norwegian Surveillance System for Communicable Diseases was 261 (figure 1). In a population of around 5.3 million people, this corresponds to an overall incidence rate of five per 100000 person-years. As demonstrated in figure 1 , almost $90 \%$ of cases were born outside Norway. The incidence rate among immigrants born in non-western countries is $>10$ times higher, at 57 per 100000 person-years, and is much higher in certain subgroups $[5,6]$. Remarkably, the increasing total incidence rates of TB between 1996 and 2013 appear to have had no influence on the steadily decreasing rates among the Norwegian-born population, indicating little transmission within Norway. This may be explained by good access to healthcare, screening on arrival of immigrants from highly endemic countries and extensive contact tracings.

In addition to information about birthplace of patients, information about birthplace of their parents is available from 2007 (figure 1). In 2017, only 16 of the 30 reported Norwegian-born cases had two Norwegian-born parents. This corresponds to an incidence rate of 0.4 per 100000 person-years

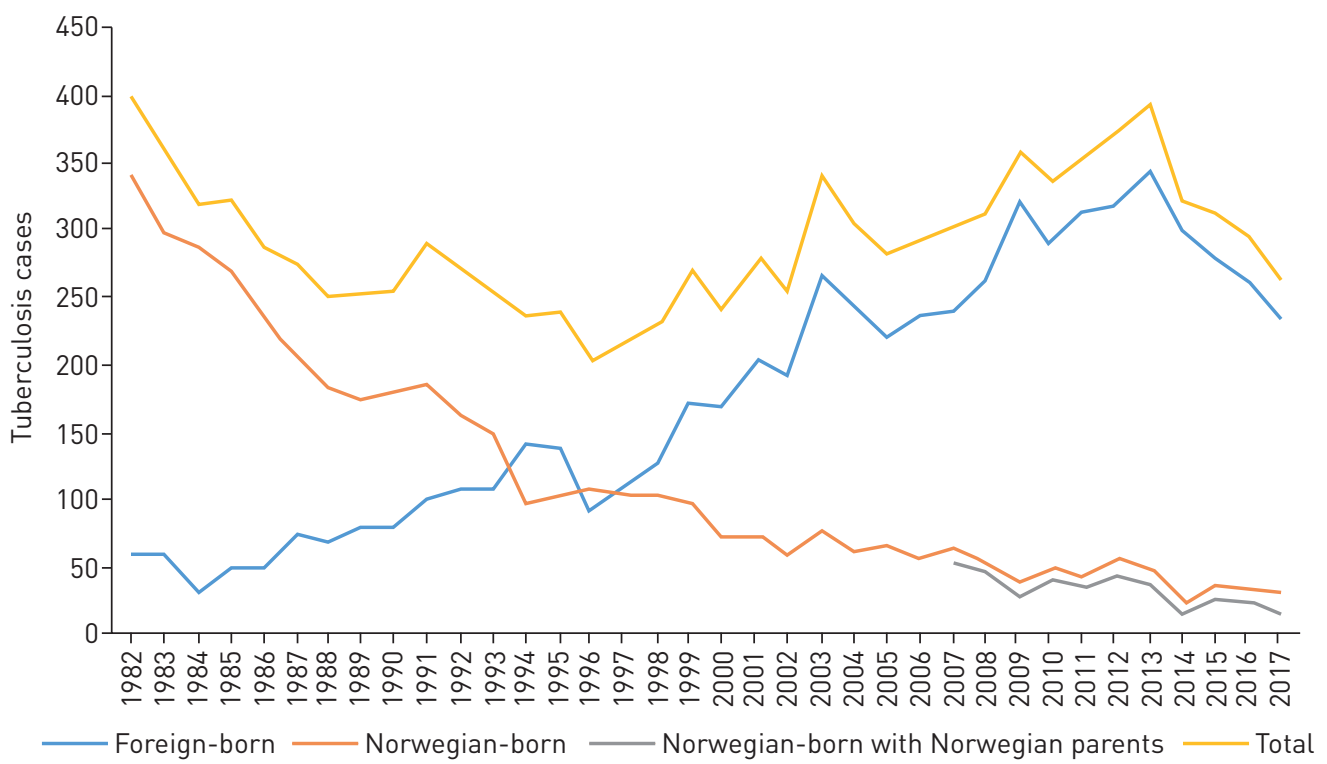

FIGURE 1 Tuberculosis cases by birthplace notified to the Norwegian Surveillance System for Communicable Diseases 1982-2017. 
among Norwegian-born persons with Norwegian heritage, which is well below the stage of pre-elimination as categorised by the World Health Organization (WHO) [7]. Importantly, there is no evidence that abolishing BCG vaccination of Norwegian-born persons with parents born in Norway has affected the risk of TB in this cohort. Despite newborn vaccination of children having at least one parent from a highly endemic country, the incidence rate in this group is 27 times higher than in children whose parents are both Norwegian-born. In recent years, approximately one-sixth of the birth cohorts have received BCG vaccination as neonates [8].

A crucial question is whether healthcare workers are at higher risk of TB than the background population. While healthcare workers are generally considered to be at increased risk [9, 10], two studies on latent infection indicate that the risk of infection among healthcare workers in Norway is very low [11, 12].

\section{Protective effect of BCG vaccination}

We performed a literature review of BCG vaccine effectiveness when administered to children and adolescents in low-incidence populations, and found a protective effect of $\sim 20 \%$ against infection and $\sim 60 \%$ against disease, lasting some 20 years [13-20]. The protective effect is highest among tuberculin-negative individuals. This is consistent with results reported by the WHO position paper on BCG published in 2018 [21].

\section{Cost}

Healthcare personnel constitute a major part of the workforce and vaccinating all requires considerable resources. Our informal estimate indicates that the direct cost of BCG vaccination is $€ 20$ per vaccine and $€ 30$ per consultation, higher if pre-vaccination testing is required. In addition, there are indirect costs such as lost working time. There is also a medical cost in the form of potential side-effects of this live vaccine, although these are rarely severe. We concluded that the cost of BCG vaccination is moderate but that the opportunity cost, i.e. the loss of what could be gained by alternative usage of the public resources, may be considerable. Furthermore, in times of international BCG vaccine shortage, this vaccine can be used to benefit populations with a higher risk of TB than Norwegian healthcare personnel.

\section{Recommendations in other countries}

We also reviewed existing recommendations for BCG vaccination in neighbouring countries. In Sweden, routine BCG vaccination of healthcare workers was discontinued in 2017 [22]. In the UK, the advice for BCG was revised in August 2018 and the vaccine is now "not usually recommended for people aged over 16 years, unless the risk of exposure is great (e.g. healthcare or laboratory workers at occupational risk through direct clinical contact with patient diagnosed with TB or contact with infectious TB materials)" [23]. In Denmark, BCG is optional for adults working with TB patients in hospitals and for high risk groups [24]. In Finland, Germany and the Netherlands, BCG is generally not given to adults $[25,26]$.

\section{Discussions with stakeholders}

In December 2017, the recommendations for BCG vaccination of healthcare workers was discussed by the Norwegian Tuberculosis Committee, an advisory board to the Norwegian Institute of Public Health representing key groups of health professional involved in TB care. There was a general consensus that BCG vaccination should be limited to those with the highest risk. The difficulty, in the absence of solid evidence, lies in defining this group.

A central topic of discussion was whether TB risk is highest among professionals caring for patients with known pulmonary TB or among those working in settings where TB is less common, such as out-patient clinics, nursing homes and immigrant services. The former comprises a limited group of healthcare workers with a high risk of TB exposure but who generally have good implementation of effective infection prevention and control measures. The latter comprises a much larger group of individuals who are much less likely to encounter TB but if they do, are at higher risk of prolonged and unprotected exposure. It might be argued that individuals in the latter group need vaccination most because, in the rare event of exposure to Mycobacterium tuberculosis, they will be less protected by effective infection prevention and control measures. However, this argument would also apply to other groups in society, such as social workers, those who work with immigrants, employees in prisons, teachers, etc. If a policy of giving BCG to all with potential exposure to TB were to be adopted, we would need to return to universal vaccination, which none of the discussants opted for.

Other topics of discussion included estimates of future TB epidemiology with an increasing immigrant population born in high-endemic countries, and the potential effect of escalating use of immunosuppressant drugs. However, it was agreed that current recommendations need to address the current epidemiological situation, not the unknown future. 
Revision of the recommendation to vaccinate all healthcare workers and students was also discussed in light of the workers' protection legislation [27]. The Norwegian Labour Inspection Authority was consulted to ensure that the employers' duty to perform a risk assessment and provide due protection was not compromised.

\section{New recommendations for BCG vaccination of healthcare personnel}

In conclusion, the Norwegian Institute of Public Health decided to abandon the recommendation to vaccinate all healthcare personnel and students. This policy was replaced by targeted BCG vaccination limited to previously unvaccinated healthcare workers and students under 35 years caring for adult patients with pulmonary TB patients in hospitals, and people involved with culture of mycobacteria in laboratories. Based on an individual risk assessment, and preferences of the employer and employee, BCG vaccination can also be considered in other situations. The age limit of 35 years was chosen because there is little evidence of effect beyond that age and is unchanged from previous recommendations.

The main justification for stopping routine BCG vaccination of all healthcare personnel was neither high cost, low vaccine effectiveness, practical obstacles nor adverse reactions, but rather the very low TB incidence in the Norwegian-born population that is not already protected by neonatal vaccination. As the incidence in this group corresponds to the stage of pre-elimination, and the risk of giving a live vaccine is not zero, we can no longer justify vaccinating all healthcare workers and students in Norway. A final report was made public in March 2018 [28] and stakeholders were informed by letter before the changes were implemented in June 2018.

Almost a century after pioneering studies demonstrated devastating rates of TB infection among nurses and doctors, the risk is extremely low for healthcare workers in Norway. In this situation, BCG vaccination has a limited role to play.

Conflict of interest: None declared.

\section{References}

1 Norwegian Institute of Public Health. Utredning om bruk av BCG-vaksine i Norge. [Exploration of the use of BCG vaccine in Norway]. Oslo, Norwegian Institute of Public Health, 2008. Available from: https://www.fhi.no/ globalassets/dokumenterfiler/moba/pdf/utredning-om-bruk-av-bcg-vaksine-i-norge-pdf.pdf

2 Heimbeck J. Tuberculous infection: attempts to prevent it by subcutaneous vaccination with B C G. Arch Intern Med 1931; 47: 901-916.

3 Bjartveit K. Olaf Scheel and Johannes Heimbeck: their contribution to understanding the pathogenesis and prevention of tuberculosis. Int J Tuberc Lung Dis 2003; 7: 306-311.

4 Heimbeck J. Tuberkuloseinfektion og tuberkulosevakcination. [Tuberculosis infection and tuberculosis vaccination]. Tiddskr Nor Loegeforen 1928; 48: 945-961.

5 Statistics Norway. Immigrants and Norwegian-born to immigrant parents. 2018. https://www.ssb.no/en/befolkning/ statistikker/innvbef Date last updated: March 2018.

6 Norwegian Institute of Public Health. Tuberkulose i Norge 2017 - med behandlingsresultater for 2016. [Tuberculosis in Norway in 2017 with treatment results for 2016]. Oslo, Norwegian Institute of Public Health, 2018. Available from: https://www.fhi.no/publ/2017/tuberkulose-i-norge-2016---med-behandlingsresultater-for2015/

7 WHO. Framework towards tuberculosis elimination in low-incidence countries 2014. http://www.who.int/tb/ publications/elimination framework/en/

8 Feiring B, Laake I, Molden T, et al. Do selective immunisation against tuberculosis and hepatitis B reach the targeted populations? A nationwide register-based study evaluating the recommendations in the Norwegian Childhood Immunisation Programme. Vaccine 2016; 34: 2015-2020.

9 Menzies D, Joshi R, Pai M. Risk of tuberculosis infection and disease associated with work in health care settings. Int J Tuberc Lung Dis 2007; 11: 593-605.

10 Baussano I, Nunn P, Williams B, et al. Tuberculosis among health care workers. Emerging Infect Dis 2011; 17: 488-494.

11 Gran G, Asmus J, Dyrhol-Riise AM. Screening for latent tuberculosis in Norwegian health care workers: high frequency of discordant tuberculin skin test positive and interferon-gamma release assay negative results. $B M C$ Public Health 2013; 13: 353.

12 Storla DG, Kristiansen I, Oftung F, et al. Use of interferon gamma-based assay to diagnose tuberculosis infection in health care workers after short term exposure. BMC Infect Dis 2009; 9: 60.

13 Roy A, Eisenhut M, Harris RJ, et al. Effect of BCG vaccination against Mycobacterium tuberculosis infection in children: systematic review and meta-analysis. BMJ 2014; 349: g4643.

14 Nguipdop-Djomo P, Heldal E, Rodrigues LC, et al. Duration of BCG protection against tuberculosis and change in effectiveness with time since vaccination in Norway: a retrospective population-based cohort study. Lancet Infect Dis 2016; 16: 219-226.

15 Michelsen SW, Soborg B, Koch A, et al. The effectiveness of BCG vaccination in preventing Mycobacterium tuberculosis infection and disease in Greenland. Thorax 2014; 69: 851-856.

16 Mangtani $\mathrm{P}$, Nguipdop-Djomo $\mathrm{P}$, Keogh $\mathrm{RH}$, et al. Observational study to estimate the changes in the effectiveness of bacillus Calmette-Guerin (BCG) vaccination with time since vaccination for preventing tuberculosis in the UK. Health Technol Assess 2017; 21: 1-54. 
17 Colditz GA, Brewer TF, Berkey CS, et al. Efficacy of BCG vaccine in the prevention of tuberculosis. Meta-analysis of the published literature. JAMA 1994; 271: 698-702.

18 Briassoulis G, Karabatsou I, Gogoglou V, et al. BCG vaccination at three different age groups: response and effectiveness. J Immune Based Ther Vaccines 2005; 3: 1.

19 Aronson NE, Santosham M, Comstock GW, et al. Long-term efficacy of BCG vaccine in American Indians and Alaska Natives: a 60-year follow-up study. JAMA 2004; 291: 2086-2091.

20 Brantsæter AB, Romanus V, Andersen PH, et al. Evidence of protective effect of BCG vaccination in persons at low risk of tuberculosis in Nordic countries. Int J Tuberc Lung Dis 2009; 13: 440-445.

21 WHO. BCG position paper. 2018. www.who.int/immunization/policy/position_papers/bcg/en/ Date last updated: February 2018.

22 The Public Health Agency of Sweden. Rekommendationer för preventiva insatser mot tuberkulos - hälsokontroll, smittspårning, behandling av latent infektion och vaccination. [Recommendations for preventive measures of tuberculosis - medical examinations, contact tracing, treatment of latent tuberculosis and vaccination]. Solna, The Public Health Agency of Sweden; 2017. Available from: https://www.folkhalsomyndigheten.se/publicerat-material/ publikationsarkiv/r/rekommendationer-for-preventiva-insatser-mot-tuberkulos-halsokontroll-smittsparning-ochvaccination/

23 Public Health England. Tuberculosis: the green book, chapter 32. 2018. www.gov.uk/government/publications/ tuberculosis-the-green-book-chapter-32 Date last updated: August 3, 2018.

24 Tuberkulosebekæmpelse i Danmark. Et nationalt tuberkuloseprogram 2018 [Tuberculosis Control in Denmark. A National Tuberculosis Program in 2018]: Danish Society of Respiratory Medicine. www.lungemedicin.dk/fagligt/ faglige-dokumenter/klaringsrapporter-1/11-tb-nationalt-2018.html Date last updated: October 5, 2018.

25 Bo M, Zotti CM. European policies on tuberculosis prevention in healthcare workers: which role for BCG? A systematic review. Hum Vaccin Immunother 2016; 12: 2753-2764.

26 Badar S, Camões Araújo T, Zwerling A, et al. The BCG World Atlas. www.bcgatlas.org/ Date last accessed: June 9, 2018. Date last updated: 2017.

27 Ministry of Labour and Social Affairs. Regulations concerning the performance of work, use of work equipment and related technical requirements. https://lovdata.no/dokument/SFE/forskrift/2011-12-06-1357 Date last updated: May 30, 2018.

28 Nøkleby H, Arnesen TM. Evaluering og revisjon av råd om BCG-vaksinasjon gjeldende fra 1. juni 2018. [Evaluation and revision of BCG vaccination from June 1st 2018]. Oslo, Norwegian Institute of Public Health, 2018. 